\title{
A atuação do Poder Judiciário na concreção das políticas públicas de saneamento básico: possibilidades e limites
}

\author{
The role of the Judiciary Power in the accomplishment of public basic \\ sanitation policies: possibilities and limits
}

Sandro Lucio Barbosa Pitassi1, Aldo Pacheco Ferreira²

DOI: $10.1590 / 0103-11042019 S 410$

RESUMO O objetivo deste artigo foi analisar as decisões judiciais proferidas em Segunda Instância pelo Tribunal de Justiça do Estado do Rio de Janeiro (TJRJ) no julgamento dos recursos relativos ao tema do saneamento básico, fixando-se como termo inicial o advento da Lei $\mathrm{n}^{\circ}$ 11.445/2007. O saneamento tem sido predominantemente tratado a partir de abordagens mais técnicas do que políticas. Nessa perspectiva, importa pensá-lo enquanto uma política pública que implique decisões, a partir de concepções e parâmetros normativos, definidas no âmbito de configurações institucionais diversas e com características mais ou menos democráticas. Considerando-se tais pontos, discute-se argumentos contrários e favoráveis acerca da judicialização da política e do ativismo judicial, fato que é uma realidade no desenho da democracia contemporânea, buscando-se, assim, explicar a relativa obscuridade dessas relações no processo de definição tanto das políticas de saúde como da política de saneamento em termos de política públicas, bem como os impactos na formulação da política de saneamento básico e as ações do campo da saúde em relação ao saneamento. Tal fenômeno é uma realidade, aguçando-se a necessidade de investigar o papel do Poder Judiciário na própria formulação e execução das políticas de saneamento da cidade do Rio de Janeiro.

PALAVRAS-CHAVE Saneamento básico. Direitos humanos. Judicialização da saúde. Política pública. Direito à saúde.

ABSTRACT This article aims to analyse the judicial decisions handed down in the Second Instance by State Court of Justice of Rio de Janeiro (TJRJ) in the judgment of appeals related to the theme of basic sanitation, establishing as the initial term the advent of Law $n^{\circ} 11.445 / 2007$. Sanitation has been predominantly addressed from more technical than political approaches. From this perspective, it is important to think about sanitation as a public policy that implies decisions, based on normative conceptions and parameters, defined in the context of diverse institutional configurations and with or less democratic characteristics. Considering those points, contrary and favourable arguments are discussed regarding the judicialization of politics and judicial activism, a fact that is a reality in the design of contemporary democracy, thus seeking to explain the relative obscurity of these relations in the process

1 Tribunal de Justiça do Estado do Rio de Janeiro (TJRJ) - Rio de Janeiro (RJ), Brasil. sandrolucio.pitassi@gmail. com

2 Fundação Oswaldo Cruz (Fiocruz), Escola Nacional de Saúde Pública Sergio Arouca (Ensp), Departamento de Direitos Humanos, Saúde e Diversidade Cultural (DIHS) - Rio de Janeiro (RJ), Brasil. of definition of both health policies and sanitation policy in terms of public policies, as well as the impacts on the formulation of basic sanitation policy and the actions of the health field in relation to sanitation. Such phenomenon is a reality, emphasizing the need to investigate the role of the Judiciary branch in the very formulation and execution of sanitation policies in the city of Rio de Janeiro.

KEYWORDS Basic sanitation. Human rights. Health's judicialization. Public policy. Right to health. 


\section{Introdução}

O saneamento básico é um conjunto de medidas para a conservação do meio ambiente e para a prevenção de doenças, ou seja, é um conjunto de intervenções multidimensionais articuladas a fatores sociais, econômicos, políticos e culturais ${ }^{1,2}$. Com o advento da Lei ${ }^{\circ} 11.445 / 07^{3}$, foi cunhado o conceito de saneamento básico como o conjunto de serviços, infraestruturas e instalações de abastecimento de água, esgotamento sanitário, limpeza urbana e manejo de resíduos sólidos e drenagem de águas pluviais urbanas.

O reconhecimento do acesso à água e ao esgotamento sanitário como direitos humanos pela Assembleia Geral da Organização das Nações Unidas (Unga) 4 e pelo Conselho de Direitos Humanos ${ }^{5}$ proporcionou novas possibilidades políticas, conceituais e analíticas para pensar esse cenário ${ }^{6}$. Desdobrou-se, então, a sinalização dos Direitos Humanos à Água e ao Esgotamento Sanitário (DHAES) como sendo direitos independentes e não implícitos no direito humano a um nível de vida que assegure saúde e bem-estar ${ }^{7}$, tal como preceitua o art. 25 da Declaração Universal dos Direitos Humanos ${ }^{8}$.

Diante da realidade brasileira e do notório deficit do serviço de saneamento básico, visto que a maior parte do esgotamento sanitário não recebe qualquer tipo de tratamento, quadro que gera inevitáveis reflexos para a qualidade de vida da população, impõe-se uma análise da atuação do Poder Judiciário no enfrentamento das ações relativas ao universo do saneamento básico. Com efeito, conquanto não exista no Brasil norma jurídica expressa sobre o direito fundamental à água e ao esgotamento sanitário, ele é decorrência de princípios constitucionais e preâmbulo para a garantia da dignidade humana e acesso a um ambiente saudável, conforme o art. 225 da Constituição Federal ${ }^{9}$.

O direito humano à água confere a todos o direito ao acesso à água suficiente, segura, aceitável, física e economicamente acessível, e o direito humano ao esgotamento sanitário a serviços que assegurem privacidade e dignidade física e economicamente acessíveis, higiênicos, seguros e culturalmente aceitáveis 6,8 . Para Marmelstein ${ }^{10}$, a dignidade da pessoa humana é um subitem dos princípios fundamentais que se liga a outros elementos essenciais, que têm, entre outras funções a embasar o direito brasileiro, os princípios elementares, que, de acordo com Pinhon(20),

são regras que contêm os mais importantes valores que informam a elaboração da Constituição Federal, são dotados de normatividade ou seja, constituem-se de regras jurídicas efetivas.

A figura 1 explicita em diagrama os direitos fundamentais, base Constituição Federal3.

Figura 1. Diagrama do conceito dos direitos fundamentais. Base - Constituição Federal³

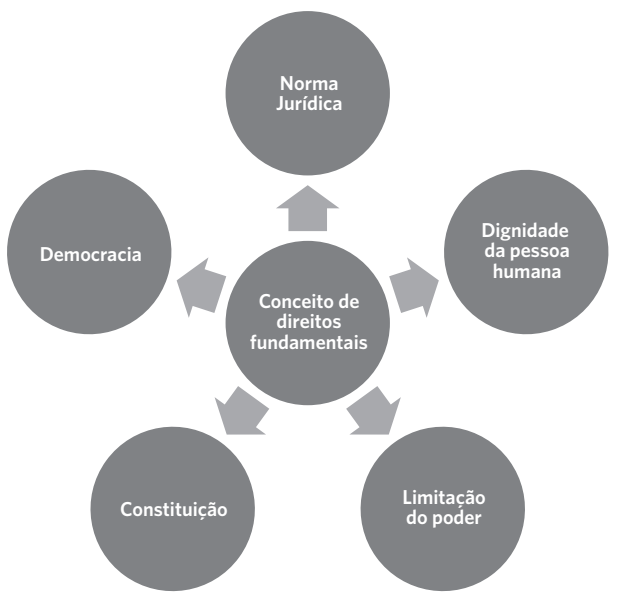


Considerando-se o conceito ampliado de saúde, e as mínimas condições de vida e ambientais, a questão do saneamento básico está intimamente relacionada com as ideias do mínimo existencial, da dignidade humana e do acesso à cidadania sanitária'12.

O direito à saúde atualmente assumiu uma conformação ampla, com previsão constitucional, verdadeiro direito fundamental, o qual tem como horizonte central a qualidade de vida dos indivíduos, o que enseja uma atuação decisiva do Poder Judiciário na entrega desse direito ${ }^{13}$.

Em que pese o entendimento no sentido de que restaria descaracterizada a função jurisdicional no campo da formulação de políticas públicas, mesmo tal raciocínio não exclui o dever de o Poder Judiciário analisar as situações de lesões a direitos ${ }^{\mathbf{1 4}}$, o que certamente diz respeito ao notório deficit de prestação de saneamento básico.

A consideração do direito à proteção à saúde como um direito constitucional e fundamental reforça a necessidade de considerar o Poder Judiciário como um dos protagonistas na concreção desse direito ${ }^{15}$, um direito de amplo espectro que certamente abarca o universo do saneamento básico.

A motivação desta pesquisa surge da análise deficitária do saneamento básico no Brasil, ganhando especial destaque o entendimento oriundo do Colendo Superior Tribunal de Justiça, proferido em julgamento do Recurso Especial 1.421.84316, tendo como Relator o Ministro Ari Pargendler, proferido em 18 de março de 2014, pela Primeira Turma, relativo à possibilidade de cobrança de tarifa de esgoto sanitário pela Companhia Estadual de Águas e Esgotos do Rio de Janeiro (Cedae), apesar da ausência de tratamento, bastando a mera coleta e transporte dos dejetos até descarte final in natura, fato que gera repercussões de várias ordens, notadamente ambientais e de saúde.

Frisa-se que decisões posteriores oriundas do Tribunal de Justiça do Estado do Rio de Janeiro (TJRJ) têm consagrado posicionamento diverso ao pacificado pelo Superior Tribunal de Justiça, entendendo-se pela ilegalidade da cobrança no caso da não prestação devida do serviço, consoante se observa, por exemplo, no julgamento da Apelação Cível $\mathrm{n}^{\mathrm{o}}$ 017396009.211.8.19.0001, proferido pela $11^{\mathrm{a}}$ Câmara Cível em 25 de novembro de 2015.

De qualquer forma, a disparidade das decisões só mostra que o assunto merece o devido estudo, pois se depara com direito intimamente ligado à dignidade da pessoa humana relativo à saúde e, mesmo que afastada a cobrança, resta o problema da não prestação efetiva do serviço e os danos concretos e potenciais aos indivíduos e ao meio ambiente, cabendo-se discutir de que forma o Judiciário pode atuar nesse campo particular de política pública, com todas as implicações e discussões que permeiam a matéria.

Destarte, este artigo visa traçar um perfil jurisprudencial no âmbito dos tribunais já mencionados, correlacionando-se com os impactos ou não das decisões judiciais produzidas na realidade, investigando-se se foram produzidos avanços e, caso positivo, em que extensão. Com efeito, desenhada a produção jurisprudencial e o cenário do saneamento básico a partir do advento da Lei n ${ }^{\circ} 11.445 / 07^{3}$, podem ser obtidos elementos que auxiliem os julgadores no exercício de suas funções, destacando-se a importância das decisões judiciais e seus potenciais como conformadoras de condutas, pois, dirigidas ao corpo social, notadamente para os gestores no processo de formulação das políticas públicas sanitárias, ora objeto de interesse, promovendo-se a saúde em última análise.

\section{Metodologia}

Estudo descritivo, de análise documental, que consiste em método de recolha e análise de dados, composto por duas fases: na primeira, ocorre a localização da fonte e a seleção dos documentos; na segunda, o tratamento das informações recolhidas e sua análise ${ }^{16}$.

Decidiu-se por analisar as decisões proferidas, em grau recursal, pelo Poder 
Judiciário do estado do Rio de Janeiro, no período de 2007 a 2018.

Direcionou-se a investigação a partir de dois enfoques delimitativos:

Pela análise da Teoria de Dworkin ${ }^{17}$, a qual apresenta como seu ponto central para análise da racionalidade da jurisdição o fato de que as decisões devem satisfazer, de forma concomitante, a critérios de segurança de direito e aceitabilidade racional, verificando-se de que forma prática da interpretação, a qual ocorre de forma construtiva, pode operar no que se refere à divisão dos poderes estatais, sem que o Poder Judiciário tome para si competências legislativas, examinando-se igualmente a problemática sob o enfoque Habermas ${ }^{\mathbf{1 8}}$.

Pela utilização da Teoria Principiológica' ${ }^{19}$ dos direitos fundamentais, visto que o exame do papel do Poder Judiciário na implementação da política de saneamento básico, inclusive no que se refere ao impacto oriundo das decisões do TJRJ, exige o estudo da otimização jurídica dos direitos em contraposição à otimização fática, investigando-se adequação e necessidade, verdadeira ponderação e sopesamento axiológico dos elementos fáticos no caso concreto ${ }^{20}$.

\section{Construção do corpus da pesquisa - a coleta de dados}

A pesquisa processual foi elaborada utilizando-se das demandas judiciais sobre saneamento básico propostas a partir de 2007, e em tramitação até 31 de dezembro de 2018, nas quais todas as demandas contaram com a mesma probabilidade de serem analisadas.

Definido o marco temporal, a pesquisa envolveu, ainda, quatro etapas: i) Aplicação do instrumento de coleta e sistematização das informações em um banco de dados; ii) Análise quantitativa das frequências das variáveis predefinidas a partir do banco de dados constituído; iii) Identificação de similitudes e diferenças entre as características das ações judiciais identificadas; e iv) Análise das possíveis relações entre as características das ações judiciais em saúde identificadas e a efetividade das políticas públicas.

O instrumento de coleta de dados foi elaborado de modo a contemplar as variáveis necessárias à realização da análise proposta na dissertação. As variáveis de interesse foram agrupadas da seguinte forma: a) Número do Processo na primeira instância; b) Data da distribuição na primeira instância; c) Decisão liminar/antecipação de tutela - decisão que, em razão da urgência, antecipa os efeitos de um ou mais pedidos da petição inicial; d) Exigências feitas pelo magistrado para a concessão da decisão liminar/antecipação de tutela; e) Réus da ação - contra qual ente público foi proposta a demanda; e f) Sentença - decisão prolatada pelo magistrado no final do processo em primeira instância.

\section{Análise dos dados}

Para analisar os dados pesquisados, foram definidas categorias e subcategorias que demonstram o que foi considerado para avaliar as decisões ministradas pelos TJRJ. A análise foi dividida em três etapas: i) pré-análise: definição do corpus por meio da leitura flutuante; formulação das categorias; ii) exploração do material: agregação dos dados brutos em características pertinentes ao conteúdo expresso nos processos; e iii) tratamento dos resultados, inferência e interpretação.

Para o desenvolvimento dessa etapa da pesquisa, foi utilizado o método da Análise de Conteúdo Temático-Categorial, que, conforme Bardin²1, consiste em descobrir os núcleos de sentido que compõem uma comunicação cuja presença ou frequência tenham algum significado para o objetivo analítico visado. As categorias de análise foram elaboradas após a leitura flutuante dos documentos recolhidos (acórdãos).

Quanto à análise temática (categorial), o texto foi desmembrado em unidades (categorias), posteriormente reagrupadas de modo a descobrir os núcleos de sentido aí presentes. Quando se fala de categorização, está-se utilizando do expediente por meio do qual 
elementos constitutivos de um conjunto são primeiramente classificados por diferenciação e, em um momento posterior, são reagrupados segundo critérios previamente definidos ${ }^{22}$. Para analisar os dados pesquisados, foram definidas categorias e subcategorias que demonstram o que foi considerado para avaliar as decisões ministradas pelos TJRJ, conforme quadro 1.

Quadro 1. Categorias e subcategorias de análise, TJRJ 2007-2018

\begin{tabular}{ll}
\hline Categorias & Subcategorias \\
\hline Universalidade & Princípio ou objetivo; soluções individuais; apropriação das soluções ou serviços; carac- \\
& terísticas sociais da população sem acesso; metas para a universalização; instrumentos e \\
& investimentos para a universalização. \\
& Política urbana e plano diretor; habitação; combate à pobreza e sua erradicação; recursos \\
Intersetorialidade & hídricos e planos de bacias; política e plano de prevenção de riscos e desastres; política \\
& de saúde; proteção do meio ambiente; promoção da igualdade racial; política de gênero. \\
& Qualidade da água; tratamento do esgoto; tratamento e disposição final de resíduos \\
Qualidade dos serviços & sólidos; controle de inundações; cortesia no atendimento ao usuário; regularidade/conti- \\
nuidade; condições técnicas e operacionais e de manutenção. & Conteúdo mínimo do plano; prestação de serviços; regulação e fiscalização; garantia do \\
Política Municipal de & atendimento essencial à saúde pública e volume mínimo per capita; direitos e deveres \\
Saneamento Básico & dos usuários; controle social; sistema de informaçães; intervenção e retomada do fundo \\
& municipal de saneamento; instrumento de aprovaça da política.
\end{tabular}

Fonte: Elaboração própria.

\section{Aspectos éticos}

A presente pesquisa foi aprovada pelo Comitê de Ética em Pesquisa da Ensp/Fundação Oswaldo Cruz, obedecendo à Resolução CNS nº 510/2016.

\section{Resultados e discussões}

Foram localizados 189 acórdãos (2007-2018) baseados nas categorias de análise ${ }^{\mathbf{2 1}}$, destacando-se os argumentos principais das decisões; e, em seguida, a análise crítica, os impactos na implementação da política sanitária, além de ressalvas pessoais sobre o teor da decisão, que são apresentados no gráfico 1, mostrando as decisões que não cumpriram os objetivos pautados na Lei $\mathrm{n}^{\mathrm{o}}$ $11.445 / 07^{3}$, representados por $97,36 \%$ dos acórdãos $(\mathrm{n}=184)$. 
Gráfico 1. Distribuição temática por categoria, TJRJ 2007-2018 (n=184)

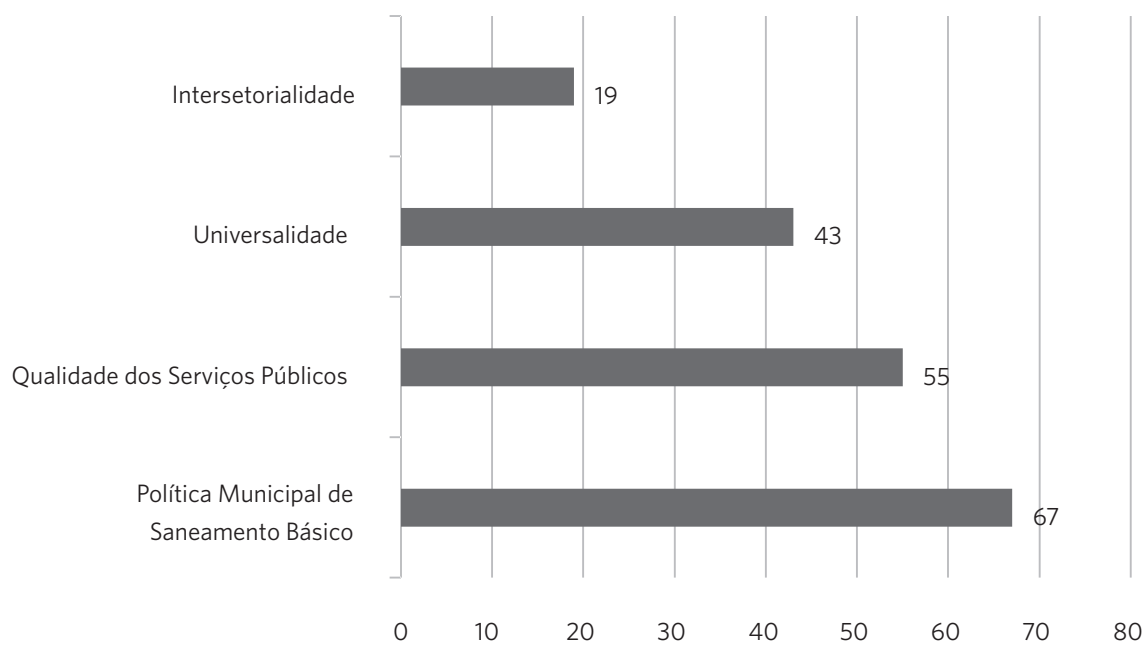

\section{Categoria: Política Municipal de Sa- neamento Básico}

Não cumpre objetivos, pois não assegura finalidade maior do saneamento básico - preocupa-se apenas com cobrança, fracionando um problema em última instância de saúde pública, postergando a solução com impactos drásticos na saúde e no meio ambiente.

Não há que se confundir rede de esgoto com rede de águas pluviais e autorizar a cobrança da tarifa utilizando-se de rede de água pluvial com lançamento dos dejetos, in natura, nos seus leitos; é forma de subsídio à poluição que mata nossos rios e ameaça o nosso mar. Não se pode prestigiar as poluidoras - ressalva nos acórdãos privilegiando o impacto ambiental, desempenhando o judiciário papel na implementação das políticas sanitárias.

Não reconhece legitimidade individual diante da qualidade do direito - transindividual -, cita Lei de saneamento para evitar que o judiciário intervenha não podendo ser atendido um cidadão. A decisão se divorcia do enfoque correto da saúde, sendo a coletividade beneficiada de forma reflexa, não cumprindo objetivo, com impacto negativo.

\section{Categoria: Qualidade dos Serviços Públicos}

Não cumpre papel atuando de forma negativa, não colaborando para a implementação da política de saneamento e a universalidade. É interessante destacar decisões judiciais que negam responsabilidade da concessionária afirmando que cabe ao ente federativo a implementação, porém, quando o ente ocupa o polo passivo da demanda, suscitam os julgadores reserva do possível, discricionariedade, limitações orçamentárias, ignorando-se a essencialidade desse primeiro e necessário estágio de dignidade por qualquer indivíduo. Entende o pesquisador que aqui não há que se falar em qualquer dose de discricionariedade pelo administrador. Serviço cuja ausência retira a condição de humano de qualquer indivíduo.

\section{Categoria: Universalidade}

Em que pese se tratar de direito indivisível, é evidente que a situação se traduziria em uma melhor qualidade de vida e saúde por todos, privilegiando-se aspectos processuais em detrimento da realidade material, entendendo o ora 
pesquisador que o princípio do notório bem-estar social pode excepcionar as amarras processuais, revelando-se que o apego à regra instrumental, processual, pode também representar um desafio à implementação da política de saneamento básico, não desempenhando, nesse caso, seu papel de implementação da política sanitária.

Não se observou discricionariedade diante da flagrante essencialidade do serviço, primeiro estágio de dignidade. Primazia do caráter instrumental em detrimento da realidade e saúde das pessoas. Não há liberdade de escolha do administrador quando se lida com direitos do núcleo mínimo da dignidade. A omissão tem consequências perversas para todos como proliferação de doenças. Exemplo - Aedes aegypti. A decisão não cumpre papel e elenca obstáculos para a política de saneamento, inclusive do próprio entendimento judicial, com impactos negativos para a coletividade.

\section{Categoria: Intersetorialidade}

Argumentos da decisão, confirmando o papel do TJRJ na implementação das políticas públicas. Desafios também abordados: escassez de recursos, recursos mal alocados em áreas desnecessárias em detrimento da área de saneamento.

Cuida-se de ação de responsabilidade civil combinado com obrigação de fazer objetivando obra para instalação de manilhamento da rede de esgoto sanitário, bem como de rede de escoamento de águas fluviais e ainda pavimentação da rua onde moram os autores.

Não se duvida das condições precárias de diversos bairros em nosso estado, principalmente, os carentes que não coadunam com os preceitos constitucionais sociais e os direitos e garantias fundamentais. No entanto, o que se deve aqui indagar é se, efetivamente, a administração pública possui condições de oferecer condições melhores à população.

Embora não se pretenda nesse voto ampliar os limites objetivos da lide, responder a essa indagação englobaria uma questão maior e que diz respeito a toda a população brasileira, e não somente à população que reside na localidade onde residem os autores.

Lamentavelmente, é notório que muitas vezes os direitos básicos de todos os brasileiros (educação, saúde, alimentação, saneamento básico, moradia, segurança, entre outros) também não são assegurados, embora sejam todos previstos em nossa Constituição.

É certo que uma administração pública inadequada colabora para tal situação, no entanto, não se pode olvidar, essa é uma realidade em nosso País, que, muitas vezes, isso ocorre pela escassez de recursos econômicos diante das inúmeras questões sociais e necessidades da vida. Destarte, conceder reparação moral às pessoas moradoras em localidades carentes, nessas circunstâncias, só aumentaria os gastos públicos, inviabilizando ainda mais as políticas públicas de relevante interesse social e até mesmo as destinadas à melhoria no saneamento básico e pavimentação das ruas.

\section{Aspectos positivos}

Com a análise da jurisprudência, buscou-se dar destaque de decisões reputadas importantes. $\mathrm{O}$ quadro 2 apresenta as decisões que cumpriram os objetivos pautados na Lei $\mathrm{n}^{\circ} 11.445 / 07^{3}$, representadas por $2,64 \%$ dos acórdãos $(n=5)$.

Em análise mais detalhada com base nos argumentos extraídos a partir da Jurisprudência encontrada, são elencados, inicialmente, os argumentos favoráveis e desfavoráveis à atuação do Poder Judiciário no que diz respeito à política de saneamento básico ante os acórdãos. 
Quadro 2. Decisões judiciais proferidas pelo TJRJ que se pautaram na Lei № $11.445 / 07^{3}$, com impacto positivo quanto ao julgamento dos recursos relativos ao tema de pesquisa (2007-2018)

\begin{tabular}{|c|c|}
\hline Acórdão & Análise de jurisprudência \\
\hline 00296462007.8 .19 .0000 & $\begin{array}{l}\text { Cumpre papel e tem impacto positivo. Ressalta descumprimento à Lei no 11.445/073 } \\
\text { e mitigação da intangibilidade do mérito administrativo. Risco iminente de lesão. } \\
\text { Entende-se que não se trata de situação de risco, mas sim de dano concreto já ocor- } \\
\text { rido. Ressalta o julgado natureza inadiável do serviço. }\end{array}$ \\
\hline 001176840.2008 .8 .19 .0000 & $\begin{array}{l}\text { Cumpre seu papel e atua positivamente na implementação da política de sanea- } \\
\text { mento. Combate à omissão do Município do Rio de Janeiro com base em questões } \\
\text { unicamente patrimoniais. Caráter de urgência da providência. }\end{array}$ \\
\hline 002351547.2009 .8 .19 .0001 & $\begin{array}{l}\text { Trata diferentemente questão da legitimidade, possibilitando a ação individual, } \\
\text { mesmo com repercussão na tutela coletiva, reconhecendo relação de consumo, não } \\
\text { vendo intromissão nos programas de governo ou violação do Princípio da Reserva, } \\
\text { reconhecendo legitimidade da concessionária. Cumpre objetivo da política sanitária e } \\
\text { destoa de representativa jurisprudência em sentido contrário. }\end{array}$ \\
\hline 00235152009.8 .19 .0001 & $\begin{array}{l}\text { Trata diferentemente questão da legitimidade, possibilitando a ação individual, } \\
\text { mesmo com repercussão na tutela coletiva, reconhecendo relação de consumo, não } \\
\text { vendo intromissão nos programas de governo ou violação do Princípio da Reserva, } \\
\text { reconhecendo legitimidade da concessionária. Cumpre o objetivo da política sanitá- } \\
\text { ria e destoa de representativa jurisprudência em sentido contrário. }\end{array}$ \\
\hline 485062008.8 .19 .0001 & $\begin{array}{l}\text { Reconhece relação de consumo-consumidor por equiparação. Rede de esgoto já } \\
\text { existe estando obstruída. Não estaria atuando o judiciário nesse caso na implemen- } \\
\text { tação da política pública. Ressalva o pesquisador, todavia seu entendimento que } \\
\text { mesmo se não existisse a rede poderia ser determinada a implantação. }\end{array}$ \\
\hline
\end{tabular}

Fonte: Lei no $11.445 / 073$.

Contrariamente à atuação jurisdicional, foram identificados os seguintes argumentos após o estudo da jurisprudência: não pode ocorrer a intervenção judicial em uma demanda individual por se deparar com direito indivisível que atinge grupo indeterminado diante do Princípio da Reserva do Possível e Separação de Poderes, além da Doutrina da Aproximação (iniciativa que mais se aproxime do desiderato constitucional, diante da impossibilidade material de solução imediata de todos os problemas da coletividade), sem falar no respeito ao Poder Discricionário da administração pública nas políticas de massa, definição de prioridades e planejamento de ações, com juízo de oportunidade e conveniência, impossibilidade de judicialização de política pública com conflito coletivo de interesses de largo espectro, já que o Judiciário não pode exercer juízo de valor sobre as opções do administrador, demandas que requerem planejamento global, integrado e interdisciplinar, não podendo o Judiciário determinar a realização, privilegiando parte da população em detrimento do restante, violando o Princípio da Igualdade, eventual condenação de danos morais inviabilizaria a implementação das políticas públicas, questões com complexidade técnica e orçamentária, obras em locais de ocupação desordenada e de grande extensão, não podendo substituir o administrador, efetivação de direitos sociais fundamentais dependentes de política pública demandam planejamento global, sendo a intervenção judicial incompatível com a cláusula pétrea de separação de poderes, impossibilidade de o Judiciário exercer controle absoluto sobre políticas públicas, devendo a intervenção ser excepcional, quando possível e exigência razoável de intervenção do Poder Público. Decisão judicial não pode determinar exercício do Poder de Polícia pelo ente político por falta de exequibilidade. 
Favoravelmente à atuação jurisdicional, foram identificados basicamente os elementos que seguem: direito social relacionado com os direitos fundamentais da saúde e meio ambiente equilibrado, devendo ser demonstrada a reserva do possível, e não simplesmente alegada. A intervenção não viola a igualdade ao revés à implementa. Não se pode admitir omissão do Estado com base em interesses meramente patrimoniais e orçamentários, desqualificando a dignidade e a saúde. Enfrentamento diverso da questão da legitimidade, possibilitando ação individual com repercussão na tutela coletiva, não havendo intromissão nos programas governamentais ou violação do Princípio da Reserva. O Judiciário não está atuando propriamente na implementação da política pública, mas apenas verificando fatos que causam danos à parte. Mitigação do Princípio da Separação de Poderes, corrigindo-se a atuação institucional que prioriza obras desnecessárias em detrimento do meio ambiente, saúde e dignidade da população. $\mathrm{O}$ processo de ponderação dos interesses em conflito enseja a intervenção jurisdicional diante das escolhas em desacordo com o desenho constitucional. A Teoria do Desenvolvimento e da Efetivação das Normas Constitucionais ressalta que as regras disciplinadoras e reconhecedoras de direitos fundamentais dão ensejo à prestação jurisdicional independentemente da classificação de eficácia limitada ou contida, buscando-se máxima efetividade das normas constitucionais. Reconhecimento da omissão e violação negativa da Constituição Federal. A reserva do possível é limitada pela intangibilidade do mínimo existencial, o qual abarca direitos sociais. A implementação do saneamento básico consiste em atividade preventiva da área de saúde, reduzindo-se risco de doenças. O Legislador (Lei $11.445 / 2007^{3}$ - art. $2^{\circ}$ ) reconhece a íntima relação entre o direito ao saneamento com o direito à saúde e ao meio ambiente equilibrado. Universalização do saneamento básico se as escolhas administrativas estão em desacordo, o Judiciário deverá corrigir diante da ofensa à regra constitucional. O Judiciário tem o poder-dever de garantir a eficácia dos direitos fundamentais. A intervenção não cuida da elaboração da política pública de saneamento básico, mas, sim, sobre a efetivação da política já existente e a inércia na prestação adequada. Superação da tese de ingerência do Poder Judiciário no campo das políticas públicas, entendendo que se trata, reversamente, da preservação do Princípio da Separação dos Poderes com base no modelo norte-americano de Freios e Contrapesos, prevalecendo a ideia de controle e vigilância de um Poder sobre o outro, desenho da nova democracia constitucional.

A pobreza deve ser vista como privação de capacidades básicas, devendo-se avaliar a ação pública destinada a reduzir desigualdade ou pobreza, sendo a relação renda e capacidade acentuadamente afetada, por exemplo, pelas condições epidemiológicas, envolvendo o desenvolvimento à expansão de liberdades básicas, sabendo-se que muitas pessoas têm pouco ou nenhum acesso a serviços de saúde, negando-se a milhões liberdades básicas de sobreviver, o que abarca saneamento básico e água tratada ${ }^{22}$.

Sendo assim, é fundamental a consideração da pobreza e do exercício deficiente de liberdades básicas na consideração da atuação jurisdicional e da fecunda possibilidade de se construir, por meio dela, uma realidade social mais justa e equânime.

A extensão da desigualdade real de oportunidades com que as pessoas se defrontam deve ser deduzida de uma variedade de características físicas e sociais que afetam suas vidas, fazendo dos indivíduos o que são ${ }^{23}$; ideia capaz de mensurar adequadamente a importância de uma política efetiva de saneamento básico e, consequentemente, da tão desejada democracia, a qual não se esgota em um plano puramente formal.

Quando se trata da justiciabilidade de uma política pública, nasce a controvérsia, cujos questionamentos para o jurista são: a) saber se os cidadãos podem exigir judicialmente a 
concretude de políticas públicas e a prestação de serviços públicos; b) saber se o Judiciário pode provocar a execução das políticas e de que forma o fazer ${ }^{24}$

Contudo, no âmbito das políticas públicas, garantidoras das condições mínimas existenciais sob condições dignas à sobrevivência do ser humano, a hodierna interpretação jurisprudencial dominante nas instâncias superiores cogita intervir judicialmente nos poderes para implementá-las. Bucci ${ }^{25}$ aponta a ocorrência de escassa jurisprudência no Brasil sobre o assunto, com decisões reiteradas na seara ambiental, exsurgindo o equilíbrio entre os poderes, questão que está distante de ser equacionada.

A Lei $\mathrm{n}^{0} 11.445^{3}$ foi aprovada depois de quase duas décadas marcadas pela ausência de regulamentação e ordenamento jurídico, e estabeleceu as diretrizes nacionais para o saneamento básico, que passa a ser compreendido como o conjunto das ações de abastecimento de água, esgotamento sanitário, manejo dos resíduos sólidos e manejo das águas pluviais. A Lei também definiu novas atribuições para os municípios, como titulares dos serviços, entre elas, a implantação da política e a elaboração do Plano Municipal de Saneamento Básico (PMSB). A gestão dos serviços passa a englobar o conjunto das atividades de planejamento, prestação dos serviços, regulação e fiscalização, todas elas acompanhadas e submetidas à participação e ao controle social. Além disso, o saneamento passa a ser orientado pelos princípios da universalização, integralidade, intersetorialidade, adoção de tecnologias apropriadas, consideração das peculiaridades locais e regionais, eficiência e sustentabilidade econômica, transparência, segurança, qualidade e regularidade.

O PMSB consiste em um dos principais instrumentos da política municipal, além de ser uma condição para a validade dos contratos de prestação dos serviços e um requisito para o acesso a recursos federais a partir de 2014. Em função disso, os municípios têm iniciado a implementação da Lei por meio da elaboração do plano, entretanto, em muitos casos, sem incorporar os princípios, o conteúdo mínimo e o processo participativo requeridos ${ }^{26}$. Por outro lado, percebe-se que parte dos planos também não emprega metodologias adequadas de planejamento ou adota métodos não condizentes com os princípios da Lei ${ }^{0} 11.445^{3}$.

O planejamento baseado em cenários, também conhecido por Prospectiva Estratégica ${ }^{27}$, vem-se consolidando como a principal técnica de prospecção e normalmente contempla as etapas: 1) formulação e análise do problema, delimitando o sistema no qual o objeto a ser planejado está inserido, geralmente de forma participativa; 2) diagnóstico do sistema, contemplando a organização e o ambiente, os processos, as árvores de competência e a análise estratégica; 3) identificação e hierarquização das variáveis que exercem maior influência na evolução do sistema; 4) identificação da dinâmica da organização, seu ambiente, desenvolvimento, estratégias dos atores e arenas; 5) redução de incertezas por meio da consulta a especialistas, para identificar tendências e detalhar cenários mais prováveis; 6) destaque dos projetos mais coerentes e opções estratégicas compatíveis com a identidade da organização e com o cenário mais provável; 7) avaliação das opções estratégicas; 8) escolhas estratégicas e hierarquização de objetivos envolvendo uma instância colegiada; e 9) definição de metas, pactuação de objetivos, definição de um sistema de monitoramento idealmente externo à organização.

A utilização do saneamento como instrumento de promoção da saúde pressupõe a superação dos entraves tecnológicos políticos e gerenciais que têm dificultado a extensão os benefícios aos residentes em áreas rurais, municípios e localidades de pequeno porte. A maioria dos problemas sanitários que afetam a população está intrinsecamente relacionada com o meio ambiente e, consequentemente, à gestão pública. Cabe destacar que, do estrito ponto de vista da saúde pública, o impacto do saneamento básico repercute em intervenções que podem influenciar sobre o homem ${ }^{28}$. Dessa forma, para uma melhor compreensão 
do problema, duas vertentes se mostram pertinentes: i) a primeira diz respeito aos modelos que têm sido propostos para explicar a relação entre ações de saneamento e a saúde, com ênfase em distintos ângulos da cadeia causal; ii) a segunda vertente consiste em classificar as doenças segundo categorias ambientais cuja transmissão está ligada ao saneamento, ou à falta de infraestrutura adequada.

Assim, a partir dessas classificações, o entendimento da transmissão das doenças relacionadas com o saneamento passa a constituir um instrumento de planejamento das ações, com vistas a considerar de forma mais adequada seus impactos sobre a saúde do homem ${ }^{30}$. Com efeito, ao governo federal, é necessário sugerir que fortaleça os seus mecanismos de apoio, tanto técnicos como financeiros, à elaboração de planos.

Ao governo estadual, recomenda-se que busque estratégias e mecanismos para apoiarem os municípios na superação dos desafios apontados, mas de forma que não comprometam a autonomia e a coordenação atribuída a esses pela Lei $\mathrm{n}^{\mathrm{O}} 11.445^{3}$.

Por fim, entende-se que o governo federal deva avaliar o conteúdo mínimo relativo às ações de saneamento que deveriam atender à legislação vigente, para que, quando liberasse recursos financeiros para os municípios, pudesse fomentar o aprimoramento dessas ações. Portanto, há que se considerar a necessidade de ampliar ações de apoio, assistência técnica, capacitação, entre outras, daquelas consideradas como medidas estruturantes, para que os governos estaduais e federais possam contribuir para a melhoria do planejamento e da gestão municipal.

\section{Considerações finais}

A dinâmica urbana vivenciada pela população no que concerne aos serviços de coleta e tratamento de esgoto, aliada aos objetivos do desenvolvimento sustentável, tem o foco de erradicar, dentre outros, a discrepância em termos de acesso ao saneamento, conforme exaustivamente demonstrado pela Organização das Nações Unidas (ONU) em seus relatórios anuais. A meta dos Objetivos do Desenvolvimento Milênio em relação ao saneamento no mundo não foi completada na vigência da agenda 2015, e novamente foi incorporada na agenda 2030 dos Objetivos do Desenvolvimento Sustentável. No Brasil, a situação não é diferente, mesmo tendo avançando no que tange às políticas públicas, o setor ainda não evolui como deveria, e a população ainda carece de serviços de esgotamento sanitário.

Em decorrência da acelerada globalização, cada vez mais, surgem novos desafios na contemporaneidade; e para acompanhar essa progressão, o poder público deve exibir políticas públicas em busca de satisfazer as novas demandas sociais para fins de promover a efetivação de direitos.

O nível mais elevado de enfrentamento das pressões sobre o meio ambiente urbano situa-se na esfera de desenvolvimento urbano vigente, segundo os modelos de incentivo e financiamento praticados pelo governo federal. É notória a ausência do poder público municipal, estadual e federal em matéria de política pública urbana nos últimos anos, seja na definição de diretrizes, seja na oferta de linhas de financiamento, particularmente em saneamento. Assiste-se, assim, à agudização do quadro de problemas urbanos, desequilíbrio e comprometimento da estrutura urbana, com reflexos diretos nos condicionantes ambientais e de saúde pública.

É evidente que o exemplo deve vir do Estado, porque, não raro, esse é o principal poluidor. A despeito das leis ambientais e urbanísticas existentes, o que vemos no setor de saneamento básico é ambientalmente insustentável. Passaram-se décadas sem investimentos maciços na rede coletora de esgotos, a qual, quando existente, não desempenha a contento seu papel. Os esgotos não são tratados e desaguam impunemente nos cursos d'água, contaminando-os. O Estado deve implementar 
as ações visando solucionar os deficit no setor de saneamento básico, por meio de formulação de políticas públicas coordenadas. Entretanto, o Governo não deve ser o único ator na formulação dessas políticas, já que a sociedade, por meio dos mais diversos setores, deve participar.

Espera-se, com análise das decisões judiciais e discussão doutrinária do que seja política pública, bem como questões relativas ao ativismo judicial, judicialização da política, reserva do possível e questões orçamentárias, no que se refere, em particular, à política de saneamento básico na cidade do Rio de Janeiro, que possam ser obtidos elementos aptos a superarem quadro de deficit desse serviço essencial, sem falar em uma melhor formulação e efetividade das próprias políticas públicas, contribuindo-se para um aperfeiçoamento da atuação dos agentes políticos, do Poder Judiciário e da própria sociedade.

Admitir um mero transporte de dejetos sem os necessários processos de tratamento representa desprezo às consequências ambientais e de saúde pública que necessariamente surgirão a partir de uma prática mitigada de um serviço notoriamente essencial.

Uma vez realizada a análise do acervo jurisprudencial, no total de 189 acórdãos proferidos pelo TJRJ a partir do advento da Lei $\mathrm{n}^{0} 11.445^{3}$, delimitando-se, dessa forma, o período de 2007 até 2018, ficou denotada uma atuação muitas vezes tímida do Poder Judiciário, privilegiando-se questões instrumentais, processuais e meramente econômicas em detrimento do substancial direito material sob enfoque, ou seja, a saúde e seu espectro público, cuja ofensa sacrifica não determinado usuário ou parcela da coletividade, mas, sim, toda a sociedade de forma direta ou reflexa.

$\mathrm{Na}$ análise jurisprudencial, encontrou-se de forma reiterada certo entendimento de que o indivíduo não poderia isoladamente buscar a tutela, por exemplo, de pavimentação e implantação da rede de esgoto no local onde reside, pois, trata-se de um direito transindividual, coletivo ou difuso, faltando legitimidade ao mesmo.
Todavia, quando a mesma pretensão aparecia em uma ação coletiva superando-se a questão processual da legitimidade, esbarrava-se em argumentos contrários à implementação da política pública, agora com o discurso das limitações orçamentarias, discricionariedade administrativa, reserva do possível, escolha pelo administrador sobre o que implementar diante da escassez de recursos etc., culminando, enfim, com a não prestação do serviço e com as toneladas de dejetos acumulando-se de forma assustadora a cada dia.

Se, em 2007, os dados já não eram satisfatórios, em 2018, com o crescimento demográfico desordenado das cidades, em particular da cidade do Rio de Janeiro e seu processo de favelização crescente e ininterrupto, o quadro só se agrava, citando-se, por exemplo, as conhecidas epidemias de dengue, zika e chikungunya, inteiramente relacionadas com a falta de infraestrutura básica.

Sabe-se que a saúde tem aspectos não só biológicos, mas igualmente sociais e psicológicos, bastando um olhar para as dezenas de áreas de ocupação irregular da cidade do Rio de Janeiro para sentir o impacto das imagens que consagram verdadeira degradação humana, quadro de horror com seres humanos cercados de dejetos e odores insuportáveis.

Abstraindo-se a questão das doenças e do aniquilamento do humano, fica a indagação do direito ao mínimo de beleza e organização de suas vidas em um ambiente agradável e digno.

O Judiciário não pode se furtar no novo conceito de democracia contemporânea de seu papel, legítimo e democrático de verdadeiro agente implementador de políticas públicas, nada havendo de anômalo nesse fenômeno próprio do século 21 , tratando-se de correta atuação jurisdicional diante da lesão a um direito constitucionalmente estabelecido (artigo $5^{\circ}$, inciso XXXV da Constituição Federal), ou seja, o de assegurar saúde e uma existência digna.

Não há lugar para espaços e omissões institucionais em uma sociedade que verdadeiramente enxergue o ser humano e 
entenda a pobreza como uma negativa de condições de cidadania básica.

O próprio atual contexto político, no qual ressurgem postulados neoliberais de uma atuação estatal menos forte no campo assistencial e privatização no campo do saneamento básico, tem que ser dimensionado com extremo cuidado quando lida com uma sociedade como a brasileira, pois vive-se em um país que ainda não consegue assegurar, por exemplo, acesso universal de sua população sequer a um vaso sanitário.

A pergunta sobre o papel do Poder Judiciário, as possibilidades de intervenção, o ativismo judicial, a discricionariedade administrativa, as limitações orçamentarias, os aspectos processuais em detrimento ao direito material e tantas outras questões indicadas após a análise da jurisprudência do presente trabalho são pontos que passam necessariamente pela percepção da realidade que se encontra ao redor, até porque o Direito é um fenômeno nitidamente social; e se isolar em uma abstração mental, onipotente e onipresente, nada proporcionará em termos de universalização de saúde, combate à pobreza e enfrentamento mesmo da violência urbana, não havendo dúvidas de que esgotos a céu aberto são campos profícuos para o nascimento e proliferação não só de doenças biológicas, mas também contribuem assustadoramente para o próprio apodrecimento da possibilidade do próprio humano, o qual se deteriora.

O Judiciário dispõe da possibilidade de intervir e contribui para um quadro mais nobre e digno, e tal perspectiva não surge por ser este um ator principal, mas um ator importante, tanto quanto os demais Poderes constituídos e a própria sociedade, pois, nessa ordem, não há lugar para protagonismos e segregações, visto que todos são igualmente necessários e têm um papel relevante a desempenhar.

O mundo exige compromisso e responsabilidade com a vida, sendo esta encarada em sentido amplo e irrestrito, lutando-se para o desaparecimento de todas as situações que não possam traduzir plenitude, respeito e inclusão.

\section{Colaboradores}

Pitassi SLB (0000-0002-7786-6588)* contribuiu para a concepção, o planejamento, a análise e a interpretação dos dados; e aprovação da versão final do manuscrito. Ferreira AP (0000-0002-7122-5042)* contribuiu para a concepção, o planejamento, a análise e a interpretação dos dados; revisão crítica do conteúdo; e aprovação da versão final do manuscrito. 


\section{Referências}

1. Soares SRA, Bernardes RS, Cordeiro Netto OM. Relações entre saneamento, saúde pública e meio ambiente: elementos para formulação de um modelo de planejamento em saneamento. Cad. Saúde pública. 2002; 18(6):1713-1724.

2. Schertenleib R. From conventional to advanced environmental sanitation. Water Sci. Technol. 2009; 51(10):7-14.

3. Brasil. Lei ${ }^{\circ} 11.445$, de 5 de janeiro de 2007. Estabelece diretrizes nacionais para o saneamento básico; altera as Leis $n^{\circ} 6.766$, de 19 de dezembro de 1979, $n^{\circ}$ 8.036, de 11 de maio de $1990, n^{\circ} 8.666$, de 21 de junho de 1993, nº 8.987, de 13 de fevereiro de 1995; revoga a Lei $\mathrm{n}^{\circ}$ 6.528, de 11 de maio de 1978; e dá outras providências [internet]. Diário Oficial da União. 6 Jan 2007. [acesso em 2017 set 19]. Disponível em: http:// www.planalto.gov.br/ccivil_03/_Ato2007-2010/2007/ Lei/L11445.htm.

4. United Nations General Assembly. Human right to water and sanitation. Geneva: United Nations General Assembly; 2010.

5. United Nations Human Rights Council. Resolution on the human right to safe drinking water and sanitation. Geneva: United Nations Human Rights Council; 2010.

6. Nahas MIP, Moura ASA, Carvalho RC, et al. Desigualdade e discriminação no acesso à água e ao esgotamento sanitário na Região Metropolitana de Belo Horizonte, Minas Gerais, Brasil. Cad. Saúde Pública. 2019; 35(4):1-17.

7. Meier BM, Kayser GL, Amjad UQ, et al. Implementing an evolving human right through water sanitation policy. Water Policy. 2013; 15:116-133.

8. United Nations. Universal Declaration of Human Rights. G. A. Res. 217A (III), at 71, U.N. GAOR, 3rd Session, 1st plenary meeting. New York: United Nations; 1948.
9. Brasil. Constituição da República Federativa do Brasil [internet]. Brasília, DF: Senado Federal; 1988. [acesso em 2018 set 15]. Disponível em: http://www.planalto.gov.br/ccivil_03/Constituicao/Constituiçao.htm.

10. Marmelstein G. Curso de direitos fundamentais. 5 . ed. São Paulo: Atlas; 2014.

11. Pinho RCR. Teoria geral da constituição e direitos fundamentais. 4. ed. rev. São Paulo: Saraiva; 2003. In: Leoneti AB, Prado EL, Oliveira SVWB. Saneamento básico no Brasil: considerações sobre investimentos e sustentabilidade para o século XXI. Rev. Adm. Pública. 2011; 45(2):331-348.

12. Corrêa D, Quadrado CM. O direito à saúde e o papel do Judiciário para a sua efetividade no Brasil. Desenvolv. Quest. 2004; 2(3):45-70.

13. Riani FAA. Constituições programática, funções estatais, políticas públicas e a (in)competência do Judiciário. Sequência (Florianópolis). 2013; 66:137-160.

14. Cuevas JC, Martini SR. Hacia la construcción de un concepto de democracia sanitaria: una mirada desde la sociología de las constituciones y la conexidad constitucional. Cad. Programa Pós-Grad. Direito PPGDir./UFRGS. 2017; 12(1):57-72.

15. Superior Tribunal de Justiça. Recurso Especial 1.421.84316 [internet]. Brasília, DF: STJ; 2011. [acesso em 2017 set 17]. Disponível em: https://stj.jusbrasil. com.br/jurisprudencia/25136210/recurso-especial-resp-1421843-rj-2011-0268849-1-stj/relatorio-e-voto-25136212.

16. Calado SS, Ferreira SCR. Análise de documentos: método de recolha e análise de dados [internet]. [local desconhecido]: DEFCUL; 2005. [acesso em 2017 abr 12]. Disponível em: http://www.educ.fc.ul.pt/docentes/ichagas/mil/analisedocumentos.pdf.

17. Dworkin R. Levando os direitos a sério. São Paulo: Martins Fontes; 2007. 
18. Habermas J. Direito e democracia: entre facticidade e validade. Volume I [internet]. Rio de Janeiro: Unesp; 1997. [acesso em 2017 abr 12]. Disponível em: https:// portalconservador.com/livros/Jurgen-HabermasDireito-e-democracia-v.I.pdf.

19. Alexy R. Teoria de los Derechos Fundamentales. Madrid: Centro de Estudios Políticos y Constitucionales; 2002.

20. Carvalho JBCL. Sobre os limites da argumentação judicial: ativismo judicial, Jürgen Habermas e Chantal Mouffe. Rev. Direito Público. 2013; 8(1):9-52.

21. Bardin L. Análise de conteúdo. Lisboa: Edições 70; 2011.

22. Sen A. Desenvolvimento como Liberdade. São Paulo: Companhia das Letras; 2000.

23. Sen A. Desigualdade Reexaminada. Rio de Janeiro: Record; 2001.

24. Bucci MPD. O conceito de política pública em direito. In: Bucci MPD, organizadora. Políticas públicas: reflexões sobre o conceito jurídico. São Paulo: Saraiva, 2006.
25. Bucci MPD. Direito administrativo e políticas públicas. São Paulo: Saraiva; 2002.

26. Pereira TST, Heller L. Planos municipais de saneamento básico: avaliação de 18 casos brasileiros. Eng. Sanit. Ambient. 2015; 20(3):395-404.

27. Buarque SC. Metodologia e técnicas de construção de cenários globais e regionais. Texto para discussão no 939. Brasília, DF: Ipea; 2003.

28. Ferreira AP. Inspeção microbiológica para avaliação da qualidade das águas ambientais. Rev. bras. farm. 2003, 84(2):61-63.

29. Ferreira AP, Cunha CLN. Environmental sustainability of water resources in the city of Rio de Janeiro, Brazil. Rev. panam. salud pública. 2005, 18(2):93-99.
Recebido em 31/07/2019

Aprovado em 23/10/2019

Conflito de interesses: inexistente

Suporte financeiro: não houve 